\title{
A FUNÇÃO SOCIAL COMO ELEMENTO CONSTITUTIVO DO NÚCLEO NORMATIVO-AXIOLÓGICO DO DIREITO DE (À) PROPRIEDADE - UMA LEITURA COMPROMETIDA COM A REALIDADE SOCIAL BRASILEIRA ${ }^{1}$
}

\section{Tiago Fensterseifer ${ }^{2}$}

Mestrando em Direito pela PUCRS - Bolsista do CNPq

Membro do Grupo de Estudos "Constituição e Direitos Fundamentais" da PUCRS (CNPq) ${ }^{3}$

Membro do NEPAD - Núcleo de Estudos e Pesquisa Ambiente e Direito da PUCRS (CNPq)

RESUMO: O presente ensaio se propõe a repensar os fundamentos do Direito Civil clássico - liberal, patrimonialista e individualista - à luz do novo paradigma constitucional - social, humano e coletivo - emplacado pela Carta Constitucional de 1988. Nesse contexto, o direito de propriedade é lido sob uma ótica tópicosistemática-construtiva com base nos novos valores fundamentais - função social, justiça social, dignidade da pessoa humana, solidariedade - que passam a integrar e constituir o seu núcleo normativo-axiológico, sempre com o foco jurídico voltado para o contexto excludente da realidade social brasileira. Diante desse quadro, a propriedade só deve existir para o sistema jurídico e ser tutelada pelo Estado na medida em que, no exercício empregado pelo seu proprietário, for verificado o cumprimento da sua função social. Para além da dimensão patrimonial da titularidade, o direito de propriedade deve ser reconhecido como um direito à propriedade, ou seja, de acesso para toda a coletividade ao mínimo existencial que ela materializa através dos direitos fundamentais à moradia, à alimentação, à renda mínima, ao trabalho na terra e à dignidade humana.

PALAVRAS-ChAVE: Função social da propriedade. Estado social e democrático de Direito. Direito de propriedade. Dignidade da pessoa humana. Constitucionalização do Direito Civil. Humanização do Direito Civil. Interpretação tópico-sistemática. Sujeito de direito. Crise do Direito Civil. Novos paradigmas do Direito Civil. Realidade social brasileira. Fundamentos do Direito Civil contemporâneo. Direitos fundamentais. Constituição. Mínimo existencial. Estado social e democrático de Direito.

\footnotetext{
${ }^{1}$ Dedico o presente ensaio a JACQUES TÁVORA ALFONSIN, paradigma ético e intelectual que levo comigo e compartilho com os amigos do NAJUP - Núcleo de Assessoria Jurídica Popular; agradeço ao amigo GUSTAVO BORSA ANTONELLO pela leitura atenta e diálogo na feitura do texto.

2 Endereço eletrônico: tiagofen@terra.com.br.

${ }^{3}$ Coordenado pelo Prof. Dr. Ingo Wolfgang Sarlet.
} 


\section{INTRODUÇÃO - UM DESASSOSSEGO NO AR}

Há um desassossego no $a r .{ }^{4}$ A nova ordem jurídica civilista, sob o prisma de um Direito Civil-Constitucional, emerge comprometida com realidade social brasileira para denunciar e romper paradigmaticamente com o modelo liberal-individualista do Direito Civil napoleônico. Nesse contexto, impõe-se a reconstrução conceitual do direito de propriedade à luz dos novos valores constitucionais agregados ao seu conteúdo, entre eles: a dignidade da pessoa humana, a justiça social e a proteção do meio ambiente. É sob o enfoque desses valores, tão importantes ao Estado social e democrático de Direito contemporâneo, que deve ser repensado o conceito e o novo regime jurídico da titularidade.

\section{O DIREITO CIVIL EM TEMPOS DE CRISE - UM OLHAR SOBRE A REALIDADE HUMANA}

Hodiernamente, em razão da incompatibilidade e ineficácia das soluções apresentadas pela ordem jurídica vigente frente às demandas sociais, pode-se constatar que o Direito ${ }^{5}$, e com especial destaque o Direito Civil, encontra-se em

${ }^{4}$ Com essa frase, BOAVENTURA, inspirado nas reflexões inquietantes formuladas por FERNANDO PESSOA em seu "Livro do Desassossego", abre o Prefácio do seu "A crítica da razão indolente", buscando resgatar um racionalismo não indiferente ou indolente, mas crítico e responsável para com a realidade humana e social.

${ }^{5}$ CLÁUDIA LIMA MARQUES destaca a crise da pós-modernidade que assola a ciência jurídica. "Com a sociedade de consumo massificada e seu individualismo crescente nasce também uma crise sociológica, denominada por muitos de pós-moderna. Os chamados tempos pós-modernos são um desafio para o direito. Tempos de ceticismo quanto à capacidade da ciência do direito de dar respostas adequadas e gerais aos problemas que perturbam a sociedade atual e modificam-se com uma velocidade assustadora. Tempos de valorização dos serviços, do lazer, do abstrato e do transitório, que acabam por decretar a insuficiência do modelo contratual tradicional do direito civil, que acabam por forçar a evolução dos conceitos do direito, a propor uma nova jurisprudência dos valores, uma nova visão dos princípios do direito civil, agora muito mais influenciada pelo direito público e pelo respeito aos direitos fundamentais do cidadão. Para alguns o pósmodernismo é uma crise de desconstrução, de fragmentação, de indeterminação à procura de uma nova racionalidade, de desdogmatização do direito, para outros, é um fenômeno de pluralismo e relativismo cultural arrebatador a influenciar o direito. Este fenômeno aumentaria a liberdade dos indivíduos, mas diminui o poder do racionalismo, da crítica em geral, da evolução histórica e da verdade, também em nossa ciência, o direito. Fenômeno contemporâneo à globalização e à perda da individualidade moderna, assegura novos direitos individuais à diferença, destaca os direitos humanos, mas aumenta o radicalismo acrítico das linhas tradicionais". MARQUES, op. cit., p. 89-90. 
crise, necessitando operar transformações em toda a sua ordem ${ }^{6}$. A crise da pósmodernidade, gerada em grande parte por uma inadequação legislativa às novas relações sociais, acaba por redimensionar os direitos fundamentais no cenário jurídico, que passam a integrar o centro axiológico dessa nova ordem em construção, rompendo com a racionalidade jurídica liberal-individualista.

Claudia Lima Marques, a partir da doutrina do professor Erik Jaime da Universidade de Heidelberg, ao referir a crise (Umbruch) e os elementos da cultura pós-moderna e seus reflexos na ciência jurídica, destaca a valorização dos direitos humanos nessa nova ordem. ${ }^{7}$

O último elemento, verdadeiro Leitmotive destacado por Jayme, é um revival dos direitos humanos, como novos e únicos valores seguros a utilizar neste caos legislativo e desregulador, de múltiplas codificações e microssitemas, de leis especiais privilegiadoras e de leis gerais ultrapassadas, de soft law e de procura de uma eqüidade cada vez mais discursiva do real.

Na esfera civilista, por exemplo, verifica-se uma grande resistência, tanto por parte da doutrina quanto por parte dos operadores do direito num plano geral, em aplicar e reconhecer o caráter normativo dos princípios e valores relativos aos direitos fundamentais - expressão positivada dos direitos humanos no plano interno dos Estados nacionais. O ranço liberal-clássico do Direito Civil ainda predomina na "manualística", contribuindo para manterem vivos preceitos liberais, há muito despidos de significado e valor, perante nova ordem de relações jurídicas massificadas e de dimensão coletiva que vigoram no atual Estado social e democrático de Direito brasileiro.

Enraizado no racionalismo-individualista, o sistema jurídico liberal induz à lógica, à generalidade e à abstração. A partir de sua orientação filosófica, exagera o papel da razão, em detrimento da experiência, utilizando como método de

${ }^{6}$ MORAIS, em análise da ciência jurídica, aponta para a crise da racionalidade jurídica individualista. "Contudo, a teoria dos interesses coletivos está longe de esgotar as possibilidades desse processo de despersonalização dos interesses. Se, do início aos meados do século $\mathrm{XX}$, a resposta jurídica à questão social e aos demais aspectos ligados ao Estado do Bem-Estar Social significaram a crise profunda da idéia de direito individual, a segunda metade deste mesmo período histórico impõe, diante do próprio esgotamento das condições vitais do planeta, ao lado de outros problemas ligados à sociedade industrial, novas questões que, para serem apreendidas pelo universo jurídico, significam o aprofundamento da crise da racionalidade individualista". MORAIS, José Luis Bolzan de. O surgimento dos interesses transindividuais. In: Revista Ciência e Ambiente - Universidade Federal de Santa Maria, n. ${ }^{\circ 17}$, Jul -Dez/1988, p. 17.

${ }^{7}$ MARQUES, op. cit., p. 95. 
investigação científica os dados obtidos por dedução, excluindo os elementos empíricos obtidos por indução. ${ }^{8}$

A partir da herança moderna ainda marcante no Direito Civil, a qual positivou o direito natural, e da neutralidade jurídica operada pelo positivismo jurídico, com sua compreensão matemática da ciência jurídica, o direito é apartado da realidade social que o permeia e o legitima, transformando-se em mera abstração ficcional. A complexidade das novas relações sociais impõe uma nova dinâmica ao direito, o qual deve criar mecanismos para recepcionar a complexidade da sociedade pósmoderna na sua dimensão humana e social.

A ciência jurídica contemporânea encontra-se em absoluta fase de transição, uma vez que está em discussão a dogmática e sua fragilidade diante dos complexos problemas trazidos pela ciência jurídica. Daí porque a inafastável necessidade em retirar o véu com que se vestiu, de certo modo, o personagem jurídico para desnudar o fenômeno jurídico à luz dos fatos e da realidade. Nessa linha, encontra-se o pensamento problemático e a dialética como modos de explicação do direito sob um prisma concreto contemporâneo (...). ${ }^{9}$

Nesse contexto de dissociação entre o mundo jurídico e o mundo real, verifica-se o que Boaventura denomina de "o desperdício da experiência"10, porquanto acaba-se por estabelecer um conjunto de relações lógicas desvinculadas da condição humana e social. O que se apreende da razão liberal é a sua neutralidade jurídica, indiferente aos fatos e tensões sociais, com seu desfecho máximo e paradigmático na Teoria Pura do Direito de Kelsen. ${ }^{11}$

Enraizado no racionalismo-individualista, o sistema jurídico liberal induz à lógica, à generalidade e à abstração. A partir de sua orientação filosófica, exagera o papel da razão, em detrimento da experiência, utilizando como método de investigação científica, os dados obtidos por dedução, excluindo os elementos empíricos obtidos por indução. Isto determinou, por longo período, a prisão do jurista à busca do sentido do direito

${ }^{8}$ RAMOS, Carmen Lucia Silveira Ramos. A constitucionalização do direito privado e a sociedade sem fronteiras. In Repensando os fundamentos do direito civil contemporâneo. Luiz Edson Fachin (coordenação). Rio de Janeiro: Renovar, 1998, p. 12.

${ }^{9}$ FACHIN, Luiz Edson. A função social da posse e a propriedade contemporânea: uma perspectiva da usucapião imobiliária rural. Porto Alegre: Fabris, 1988, p. 13.

10 SANTOS, Boaventura de Sousa. A crítica da razão indolente: contra o desperdício da experiência. 3.ed. São Paulo: Cortez, 2001. 
exclusivamente no texto legal, afastada a preocupação com realizar justiça, e ao positivismo, chegando a Kelsen e sua teoria pura, divorciada da realidade. ${ }^{12}$

A estrutura fechada do sistema liberal, mantenedora "a todo custo" do status quo e das elites que ocupam o poder, não possibilita o transito jurídico dos valores emergentes da sociedade contemporânea. Ao não compreender a vida e a sociedade como fontes criadoras e legitimadoras do direito - o sistema liberal perde a sua legitimidade e razão de ser no universo jurídico contemporâneo, ainda mais quando se vive na realidade de um país em desenvolvimento e com a segunda pior distribuição de renda do mundo ${ }^{13}$. De instrumento de emancipação e transformação social, o direito passa a instrumento de regulação e dominação da sociedade. De meio de concretização da dignidade da pessoa humana, do bem-estar e da paz social, o direito passa a ser tomado como um fim em si mesmo, a serviço "única e exclusivamente" da mesma elite que já impera no Brasil há mais de cinco séculos.

Dessa forma, impõe-se ao novo jurista um desapego à forma e às soluções matemáticas da ciência jurídica e um resgate do seu conteúdo real e humano. $\mathrm{O}$ valor e o fato devem recuperar os seus espaços tomados pela hipertrofia da norma. ${ }^{14}$ "Desde a famosa Teoria Tridimensional de Miguel Reale, os bacharéis estão acostumados com o conceito de valor; o que falta é transportá-lo da 'ilha' da Filosofia para o Direito Constitucional e o trabalho diário do operador jurídico." ${ }^{15}$

A visão clássica do Direito Civil, de um modo geral, insensível às transformações sociais ocorridas na estrutura do Estado e da sociedade brasileira ao longo dos últimos séculos, nega-se a assimilar os novos conceitos e demandas sociais. Ao ensinar apenas como manejar os conceitos abstratos, a doutrina clássica

\footnotetext{
11 "Quando a si própria se designa como 'pura' teoria do Direito, isto significa que ela se propõe garantir um conhecimento apenas dirigido ao Direito e excluir deste conhecimento tudo quanto não pertença ao seu objecto, tudo quanto se não possa, rigorosamente, determinar como Direito. Quer isto dizer que ela pretende libertar a ciência jurídica de todos os elementos que lhe são estranhos. Esse é o seu princípio metodológico fundamental”. KELSEN, Hans. Teoria pura do direito. 4.ed. Coimbra: Armênio Amado, 1979, p. 17.

12 RAMOS, op. cit., p. 12.

${ }^{13}$ Foi divulgado recentemente no Jornal Zero Hora (dia 02.06.2005, p. 5) o resultado de pesquisa realizada pelo Instituto de Pesquisa Econômica Aplicada (IPEA), onde o Brasil aparece como o segundo país no mundo com pior distribuição de riqueza, entre 130 países pesquisados, perdendo apenas a posição de liderança para o país africano de Serra Leoa. Os dados são relativos aos anos de 2000 e 2001 e foram retirados do Relatório de Desenvolvimento Mundial das Nações Unidas.

${ }^{14}$ Aqui, refere-se à concepção civilística-clássica de norma que a identifica como a regra em si, não atribuindo e admitindo o caráter normativo dos princípios.
} 
não permite a compreensão da realidade, impossibilitando a sua transformação. $O$ direito, no entanto, deve se constituir a partir da realidade histórica que o legitima e dá razão.

O estudo do direito - e, portanto, também do direito tradicionalmente definido "privado" não pode prescindir da análise da sociedade na sua historicidade local e universal, de maneira a permitir a individualização do papel e do significado da juridicidade na unidade e na complexidade do fenômeno social. O Direito é ciência social que precisa de cada vez maiores aberturas: necessariamente sensível a qualquer modificação da realidade, entendida na sua mais ampla acepção. ${ }^{16}$

Com suas raízes políticas no Estado Liberal e jurídicas no Código Napoleônico de 1804, a doutrina civilista clássica projetou, e ainda projeta, suas luzes sobre a visão jurídica de grande parte da doutrina contemporânea, impedindo e bloqueando a passagem da luz solar, ao colocar os juristas atuais nas mesmas condições dos prisioneiros do "Mito da Caverna", de Platão ${ }^{17}$ - distantes da realidade, mas defensores cegos dos dogmas clássicos, a ponto de matar ou morrer pela manutenção do status quo excludente da sociedade brasileira.

Nesse sentido, contrapondo o atual contexto socioeconômico vivenciado pela sociedade brasileira contemporânea à ordem jurídica vigente, no plano das relações jurídicas acobertadas pelo Direito Civil, verifica-se uma incompatibilidade abissal entre a dinâmica e criatividade das relações sociais frente à evolução do direito. O Direito Civil, ao enclausurar e tornar abstrata a pessoa humana na sua codificação, não consegue, nem de longe, acompanhar a sociedade no seu constante caminhar.

A crise do sistema clássico do Direito Civil suscita, antes de mais nada, questões concernentes à sua historicidade, à análise da inter-relação entre Direito e Sociedade, e ao princípio de dinamismo que impinge ao Direito seu eterno diálogo com o meio social, seu

${ }^{15}$ KRELL, Andreas. Direitos sociais e controle judicial no Brasil e na Alemanha: os (des)caminhos de um direito constitucional comparado. Porto Alegre: Sergio Antonio Fabris Editor, 2002, p. 77.

${ }^{16}$ PERLINGIERI, Pietro. Perfis de direito civil: introdução ao direito civil constitucional. Tradução de Maria Cristina De Cicco. Rio de Janeiro: Renovar, 1999, p. 01.

${ }^{17}$ MARCONDES, Danilo. Textos básicos de filosofia: dos Pré-socráticos a Wittgenstein. 2 ed. Rio de Janeiro: Jorge Zahar Editora., 2000, p. 39/42. 
tempo e seu espaço. Também se distancia da análise dos conceitos frente à concretude dos fatos que a eles se apresentam. ${ }^{18}$

Não há como negar a crise do sistema civilista clássico, necessitando-se retomar o foco da visão jurídica para a realidade social presente. Impõe-se, no plano jurídico atual, que o passado liberal (não desconsiderando a sua importância para a compreensão histórica do direito) seja deixado para trás e que o direito passe a caminhar, se não de mãos dadas, ao menos próximo da sociedade. Esta, como sujeito maior na construção da cultura jurídica, objetiva, através da ordem normativa, não a sua regulação e o seu enclausuramento, mas a sua emancipação e a sua liberdade.

Quanto mais o ordenamento jurídico se identifica ou tende a se identificar com aquele social, político, econômico, tanto mais a identificação do valor fundado no critério normativo será conforme a realidade efetiva. Quanto mais o dado normativo souber se adequar à realidade social, tanto mais a realidade se apresentará de forma homogênea e unitária. Isso, talvez, não aconteça jamais, por causa da contínua evolução do direito em relação à sociedade. É preciso, de todo modo, ter consciência e escolher, pelo menos como linha de tendência, a contínua, constante adequação da realidade social e econômica-política à realidade jurídica e vice-versa. ${ }^{19}$

Parafraseando Eduardo Galeano, "a primeira condição para modificar a realidade consiste em conhecê-la". ${ }^{20}$ Dessa forma, é preciso que o universo jurídico privatista amplie a sua visão, focalizando-a sob as tensões sociais latentes na sociedade brasileira. Tomando por base o quanto alegado por Galeano, é preciso que o "direito" se infiltre em todos os espaços sociais, possibilitando a superação do quadro excludente e marginalizante que hoje se apresenta.

${ }^{18}$ FACHIN, Luiz Edson. Teoria crítica do Direito Civil. Rio de Janeiro: Renovar, 2000, p. 22.

${ }^{19}$ PERLINGIERI, Pietro. Perfis de direito civil: introdução ao direito civil constitucional. Tradução de Maria Cristina De Cicco. Rio de Janeiro: Renovar, 1999, p. 31.

${ }^{20}$ GALEANO, Eduardo. As veias abertas da América Latina. 12 ed. Tradução de Galeno de Freitas. Rio de Janeiro: Paz e Terra, 1981, p. 287. 


\section{HUMANIZAÇÃO DO DIREITO CIVIL - DO SUJEITO DE DIREITO ABSTRATO AO SUJEITO DE CARNE E OSSO}

Com o processo de constitucionalização, outro fenômeno que se verifica na reconstrução do Direito Civil é a sua "humanização" - na doutrina, encontram-se ainda os conceitos "despatrimonilização"21 e "repersonalização". Tal consiste, basicamente, em retirar-se o patrimônio do centro axiológico do ordenamento jurídico civilista, ainda sob uma concepção liberal do Direito Civil, substituindo-o pela dignidade da pessoa humana, princípio matriz do nosso sistema jurídico. ${ }^{22}$ Dessa forma, impõe-se a normatividade dos princípios constitucionais ${ }^{23}$, exercendo sua eficácia imediata nas relações de Direito Civil.

No caso brasileiro, a introdução de uma nova postura metodológica, embora não seja simples, parece facilitada pela compreensão, mais e mais difusa, do papel dos princípios constitucionais nas relações de direito privado, sendo certo que a doutrina e a jurisprudência têm reconhecido o caráter normativo de princípios como o da solidariedade social, da dignidade da pessoa humana, da função social da propriedade, aos quais se tem assegurado eficácia imediata nas relações de direito civil. ${ }^{24}$

Nesse contexto, a concepção de sujeito de direito consagrada pelo Direito Civil clássico é destituída de qualquer conteúdo propriamente humano. Ela parte de uma compreensão abstrata do indivíduo, considerando apenas os direitos e deveres

21 "As relações patrimoniais são funcionalizadas à dignidade da pessoa humana e os valores sociais insculpidos na Constituição de 1988. Fala-se, por isso mesmo, de uma 'despatrimonialização do direito privado', de modo à bem demarcar a diferença entre o atual sistema em relação àquele de 1916, patrimonialista e individualista." 80 anos do Código Civil brasileiro: um novo Código atenderá às necessidades do país? Revista Del Rey, Belo Horizonte, $\stackrel{\text { a }}{1}$, n. 1, dez. 1997.

22 'Numa expressão, o Direito Civil deve, com efeito, ser concebido como 'a serviço da vida' a partir de sua raiz antropocêntrica, não para repor em cena o individualismo do século XVIII, nem para se afastar do tecnicismo e do neutralismo. Não sucumbir, enfim, ao saber virtual." FACHIN, Luiz Edson. Teoria crítica do Direito Civil. Rio de Janeiro: Renovar, 2000, p. 16.

\footnotetext{
${ }^{23}$ Nesse sentido, convém destacar a densificação constitucional que sofre o princípio da boa-fé objetiva, consagrado nos arts. 51, IV, do Código de Defesa do Consumidor e 422 do novo Código Civil Brasileiro."O princípio da boa-fé reaparece (...) funcionando como o elo entre o direito contratual e os princípios constitucionais. Sob a ótica civil-constitucional, a boa-fé representa, pois, a valorização da pessoa humana em oposição à senhoria da vontade expressa pelo individualismo jurídico. O contrato vem configurado como um espaço de desenvolvimento da personalidade humana; uma relação econômica jurídica em que as partes devem colaboração umas com as outras com vistas à construção de uma sociedade que a Constituição quer livre, justa e solidária". Maria Celina Bodin de Moraes apud TEPEDINO, Gustavo. Código Civil, os chamados microssistemas e a Constituição: premissas para uma reforma legislativa. In Problemas de Direito CivilConstitucional. Gustavo Tepedino (coordenador). Rio de Janeiro: Renovar, 2000, p. 14.

${ }^{24}$ TEPEDINO, Gustavo. Código Civil, os chamados microssistemas e a Constituição: premissas para uma reforma legislativa. In Problemas de Direito Civil-Constitucional. Gustavo Tepedino (coordenador). Rio de Janeiro: Renovar, 2000, p. 12.
} 
constituídos a partir do ordenamento jurídico civilista. Em outras palavras, o sujeito jurídico é quem transita dentro deste universo jurídico exclusivista, contratando, adquirindo propriedade, constituindo herança, etc. Todas as relações deste ser jurídico estão relacionadas à sua capacidade patrimonial. Quanto mais patrimônio o sujeito jurídico tem, mais é livre o seu trânsito pelo cosmos do ordenamento civil clássico.

O evidente artificialismo da noção clássica faz alargar a distância entre o que a lei civil estabelece como sendo pessoa e o indivíduo homem, este a merecer proteção não pelo que tem, mas pelo que é. Por certo, não deve a proteção patrimonial suplantar a proteção dos seres humanos. No entanto, analisadas as disposições civis brasileiras codificadas, demonstra-se nítido o seu caráter essencialmente patrimonialista, vez que o ser sujeito de direito depende de sua aptidão para, seguindo igualmente os parâmetros ditados pelo sistema, ter patrimônio. ${ }^{25}$

O sujeito de direito, em primeira análise, é um ser vivo (da espécie humana), que come, habita um território, constitui família, tem desejos, angústias e sonhos, e, de certa forma, combate as adversidades do seu meio social e natural a fim de possibilitar a sua sobrevivência e existência digna. É para este sujeito de direito que o Direito Civil deve estar voltado, devendo a abstração jurídica ser preenchida com carne e osso. Ao direito, e conseqüentemente ao Direito Civil também, é imposta a responsabilidade de zelar por toda a existência humana, possibilitando o acesso de todos às condições mínimas necessárias à sobrevivência - não apenas material, mas também existencial.

$\mathrm{Na}$ ordem jurídica, a pessoa é um elemento científico, um conceito oriundo da construção abstrata do direito. Em outras palavras, é a técnica jurídica que define a pessoa traçando seus limites da atuação. Esse delineamento abstrato decorre substancialmente, da noção de relação jurídica como base do Direito Civil. Em um sistema assente na estrutura formal da relação jurídica, as pessoas são consideradas sujeitos, não porque reconhecidas a sua natureza humana e a sua dignidade, mas na medida em que a lei lhes atribui faculdades ou obrigações de agir, delimitando o exercício de poderes ou exigindo o cumprimento de deveres. ${ }^{26}$

${ }^{25}$ MEIRELLES, Jussara. O ser e o ter na codificação civil brasileira - do sujeito virtual à clausura patrimonial. In Repensando os Fundamentos do Direito Civil Contemporâneo. Luiz Edson Fachin (Coordenador). Rio de Janeiro: Renovar, 1998, p. 92-93.

${ }^{26}$ MEIRELLES, op. cit., p. 89. 
$\mathrm{Na}$ nova compreensão da ordem civil-constitucional, um primeiro passo necessário é a reconstrução do ser jurídico. Nesse sentido, é necessária a distinção essencial entre o "ser jurídico" e o "ter jurídico", que, para a nova ordem axiológica constitucional, não guardam nenhuma relação intrínseca. É buscada uma igualdade material e não apenas formal para as relações jurídicas. O patrimônio não pode mais ser o parâmetro para quem ingressa e para quem é excluído da ordem jurídica (considerando-se que não possa haver exclusões).

Pessoa, nessa ordem de idéias, é aquele que compra, que vende, que testa; enfim, aquele que reúne condições de desenvolver atividades adequadas ao sentido marcadamente proprietarista do Código Civil Brasileiro. Ser pessoa é adequar-se, perfeitamente, aos parâmetros estabelecidos pelo ordenamento; é traduzir, de modo concreto, a imagem conceitual ditada pelas normas. Não é difícil concluir, portanto, que a pessoa que o Código Civil descreve não corresponde àquela que vive, sente e transita pelos nossos dias. É que os valores pessoais, os desejos, a intenção de ter reconhecida a sua dignidade não encontram correspondência na abstração de uma figura que o sistema pretende como pessoa, como sujeito de direito. Esse sujeito que a lei civil define como tal é o homem, mas esse mesmo homem definido como sujeito de direito muitas vezes passa pelo mundo sem ter tido o mínimo de condições necessárias à sua sobrevivência. Traçando-se uma espécie de paralelo tem-se, de um lado, o que se pode denominar pessoa codificada ou sujeito virtual; e, do lado oposto, há o sujeito real, que corresponde à pessoa verdadeiramente humana, vista sob o prisma de sua própria natureza e dignidade, a pessoa gente. ${ }^{27}$

A distinção entre pessoa natural (ou humana) e pessoa física (ou jurídica) ${ }^{28}$ não se torna possível com os valores humanos que hoje dão os alicerces da nova ordem jurídica. A concepção abstrata de indivíduo, destituído de qualquer conteúdo material, que imperou na doutrina clássica - e para alguns doutrinadores e operadores jurídicos ainda impera -, é combatido frontalmente com o conteúdo constitucional inserido na ordem jurídica civil. O princípio da dignidade da pessoa

${ }^{27}$ MEIRELLES, op. cit., p. 90-91.

${ }^{28}$ O novo Código Civil não inova neste sentido, porquanto é perceptível a distinção existencial e conceitual da pessoa que transita nas relações do seu universo jurídico e a pessoa natural. Tal distinção é perceptível, entre outros, nos seus artigos $6^{\circ} \mathrm{e} 21$. 
humana preenche de vida a ficção jurídica criada pela concepção individualistaliberal de sujeito de direito. ${ }^{29}$

Na ordem de princípios como a dignidade, igualdade, especificamente na área civil, boa-fé, bons costumes, reciprocidade, confiança, lealdade, não lesividade, vulnerabilidade, etc., com a incidência direta das normas constitucionais, nas relações interprivadas, o Direito Civil passa a centrar-se mais na pessoa humana do que na patrimonialidade, assim como mais no coletivo do que no individual. ${ }^{30}$

A ordem civil, assim como todo o ordenamento jurídico, também guarda na realização dos direitos fundamentais a sua função jurídica maior. Com o surgimento deste "novo" Direito Civil, centralizado nos valores humanos, o ordenamento civilista torna-se sensível à dinamicidade das demandas sociais.

É necessário que, com força, a questão moral, entendida como efetivo respeito à dignidade da vida de cada homem e, portanto, como superioridade deste valor em relação a qualquer razão política da organização da vida em comum, seja reposta ao centro do debate na doutrina e no Foro, como única indicação idônea a impedir a vitória de um direito sem justiça. $^{31}$

A reorientação de princípios e valores a que está condicionado o Direito Civil pelo texto constitucional faz com que a sua leitura se faça no sentido constituiçãocódigo, em detrimento da sua leitura código-constituição. Tudo o que não encontrar suporte no texto constitucional, mesmo que expresso em legislação civil, estará fora do sistema e do ordenamento jurídico. A partir dessa racionalidade, é perceptível o valor fundamental atribuído à dignidade da pessoa humana e ao bem-estar social na nova leitura que se faz do agora Direito Civil-Constitucional. O patrimônio perdeu espaço em favor a valores de natureza humana existencial e social.

Esta despatrimonialização do direito civil não significa a exclusão do conteúdo patrimonial no direito, mas a funcionalização do próprio sistema econômico, diversificando a sua

29 "Inicialmente se faz necessário compreender como o sistema clássico trata o sujeito, ou seja, as pessoas. O sujeito de direito e as pessoas são captados por uma abstração do mais elevado grau. O sujeito in concreto, o homem comum da vida não integra esta concepção, e o Direito imagina um sujeito in abstrato e cria aquilo que a doutrina clássica designou de sujeito jurídico." FACHIN, Luiz Edson. Teoria crítica do Direito Civil. Rio de Janeiro: Renovar, 2000, p. 55.

30 ARONNE, Ricardo. Propriedade e Domínio - Reexame sistemático das noções nucleares de Direitos Reais. Rio de Janeiro: Renovar, 1999, p. 41.

31 PERLINGIERI, Pietro. Perfis de direito civil: introdução ao direito civil constitucional. Tradução de Maria Cristina De Cicco. Rio de Janeiro: Renovar, 1999, p. 23. 
valoração qualitativa, no sentido de direcioná-lo para produzir respeitando a dignidade da pessoa humana (e o meio ambiente) e distribuir as riquezas com maior justiça. ${ }^{32}$

Garrido Peña, a partir da leitura que faz da doutrina de Rawls, contrapõe os princípios constitucionais da liberdade e da igualdade, como valores intrinsecamente relacionados no contexto societário contemporâneo, alertando para um limite social imposto à liberdade individual.

J. Rawls define como una relación de justicia aquella que se asienta sobre el principio de: "Todo individuo tiene derecho al máximo grado de libertad posible que sea compatible con igual libertad para todos". La aceptación de este principio comporta que todo plus de libertad que sea superior a otro conlleva una imposición y una expropiación de la libertad del otro. Desde esta razonable definición de Rawls, la igualdad y libertad son miembros de un mismo par ordenado. La libertad individual tiene como límites la libertad del otro. Y la libertad, desde el punto de vista social, solo puede ser vista como el reconocimiento de la igualdad en el disfrute de las libertades individuales. Es el principio social de la igualdad el que hace posible el reconocimiento efectivo de las libertades individuales de todos los miembros de la sociedad. Y, por otro lado, la autolimitación colectiva de la libertad individual es la condición de posibilidad de la diferencia e la singularidad del ejercicio individual de las libertades. Cuando una libertad individual transgrede el consenso constituyente sobre esta regla de oro de la igualdad de libertades usurpando la libertad del otro, entonces no estamos ante un ejercicio de libertad sino de poder, como nos dice Ferrajoli (Derecho y razón. Teoría del garantismo penal. Barcelona: Trotta, 1995, p. 908-912). A este límite le llamaremos el límite social de la libertad individual. ${ }^{33}$

A compreensão da propriedade no sistema jurídico brasileiro contemporâneo, a fim de abordá-la de forma comprometida com o seu valor social, requer um estudo a partir das suas raízes históricas na formação e na constituição da própria sociedade brasileira. Nesse contexto, a propriedade apresenta-se como elemento essencial para determinar a estrutura econômica e social do Estado de Direito. No Brasil, ao longo dos cinco séculos posteriores ao seu "redescobrimento",

${ }^{32}$ Citação de Pietro Perlingieri apud RAMOS, op. cit., p. 16.

33 PEÑA, Francisco Garrido. De como la ecologia política redefine conceptos centrales de la ontologia jurídica tradicional: libertad y propiedad. In $\mathbf{O}$ novo em Direito Ambiental. Marcelo Dias Varella e Roxana Cardoso Brasileiro Borges (Organizadores). Belo Horizonte: Del Rey, 1998, p. 216-217. 
a titularidade vem sendo tomada como forma de marginalização e exclusão social ${ }^{34}$. Os limites entre o exercício de um direito e o exercício de um poder são quase imperceptíveis na ordem econômica capitalista, mas as suas conseqüências são desastrosas para toda a sociedade, acarretando em profunda exclusão e marginalização social.

\section{UMA CONCLUSÃO IMPOSTA PELA REALIDADE BRASILEIRA E PELA NOVA ORDEM CONSTITUCIONAL: A FUNÇÃO SOCIAL COMO ELEMENTO CONSTITUTIVO DO NÚCLEO NORMATIVO-AXIOLÓGICO DO DIREITO DE (À) PROPRIEDADE}

No contexto jurídico contemporâneo - mas, principalmente após a promulgação da Constituição de 1988 -, não se pode mais conceber a propriedade sem a sua funcionalização, nos estritos termos dos preceitos constitucionais a ela pertinentes. ${ }^{35}$ A função social da propriedade, consagrada por vez primeira como direito fundamental da pessoa humana na Carta Magna de 1988, institui-se como elemento constitutivo do próprio direito de propriedade. ${ }^{36}$ De mera limitação ao exercício do direito de propriedade, a função social da propriedade passa a constituir-se de elemento intrínseco normativo-axiológico da própria titularidade.

Contudo, quer nos parecer que a função social da propriedade não deva ser visualizada como um conjunto de princípios programáticos. Temos que a melhor concepção é aquela que afirma ser a função social elemento constitutivo do conceito jurídico de propriedade. Importa dizer que a função social não é um elemento

34 "Cada vez mais a propriedade deixa de ser explicável como um poder sobre as coisas para ser um poder sobre os outros homens: de uma apropriação do mundo material presente passa a ser uma apropriação do trabalho alheio e da riqueza futura." LOPES, José Reinaldo de Lima. 0 direito na história: lições introdutórias. São Paulo: Max Limonad, 2000, p. 408.

35 Artigos 5, XXIII, 170, III, 184, caput, 182, caput e $\S 2^{\circ}$, e 186 da Constituição Federal de 1988. Destaca-se que os artigos de lei citados consagram a função social da propriedade como direito fundamental da pessoa humana e como princípio geral a orientar toda a atividade econômica.

36 "A doutrina se tornara de tal modo confusa a respeito do tema, que acabara por admitir que a propriedade privada se configura sob dois aspectos: a) como direito civil subjetivo e b) como direito público subjetivo. Essa dicotomia fica superada com a concepção de que a função social é elemento da estrutura e do regime jurídico da propriedade; é, pois, princípio ordenador da propriedade privada; incide no conteúdo do direito de propriedade; impõe-lhe novo conceito". SILVA, José Afonso da. Curso de Direito Constitucional Positivo. 6.ed. São Paulo: Malheiros, 1994, p. 241 
externo, um mero adereço do direito de propriedade, mas elemento interno sem o qual não se perfectibiliza o suporte fático do direito de propriedade. Em obra clássica, afirma Stefano Rodota que a função social não pode ser identificada com a banda externa da propriedade, mas que se identifica com o próprio conteúdo da propriedade. $^{37}$

Dessa forma, concebendo-se a função social como elemento e pré-requisito existencial do direito de propriedade ${ }^{38}$, a constituição jurídica deste último está condicionada ao cumprimento daquela na realidade fática. ${ }^{39} \mathrm{~A}$ propriedade que não atende à sua função social não existe para 0 direito ${ }^{40}$, o que acarreta na impossibilidade de sua proteção e legitimidade perante a ordem jurídica instituída. ${ }^{41}$

A propriedade dotada de função social, que não esteja a cumpri-la, já não será mais objeto de proteção jurídica. Ou seja, já não haverá mais fundamento jurídico a atribuir direito de propriedade ao titular do bem (propriedade) que não está a cumprir sua função social. Em

37 SILVEIRA, Domingos Sávio Dresch da. A propriedade agrária e suas funções sociais. In 0 direito agrário em debate. Domingos Sávio Dresch da Silveira e Flávio Sant’Ánna Xavier (organizadores). Porto Alegre: Livraria do Advogado, 1998, p. 13.

38 FACHIN afirma que tal entendimento levaria a desnecessidade de indenização relativamente aos imóveis que descumprem o seu desígnio social imposto pela ordem constitucional por parte do Estado, uma vez que onde não há função social, não há propriedade. "Se, ao invés de a propriedade rural ter uma funcão social, ela se tornar funcão social, concluir-se-á que não há direito de propriedade sem funcão social. Essa concepcão poderia permitir a um Estado democrático arrecadar os imóveis rurais que sejam enquadráveis nessa categoria sem indenizacão. Se não há direito, logo, não há o que indenizar. Entender, hoje, que não há propriedade rural sem funcão social é construcão teórica correta, mas cuja base jurídica ainda deve ser conquistada". FACHIN, Luiz Édson. Terras devolutas e a questão agrária: anotações preliminares para um ensaio. In: Revista dos Tribunais, V. 629, Março/1988, p. 56.

39 “AÇÃO REIVINDICATÓRIA. LOTES DE TERRENO TRANSFORMADOS EM FAVELA DO TADA DE EQUIPAMENTOS URBANOS. FUNÇÃO SOCIAL DA PROPRIEDADE. DIREITO DE INDENIZAÇÃO DOS PROPRIETÁRIOS. Lotes de terreno urbanos tragados por uma favela deixam de existir e não podem ser recuperados, fazendo, assim, desaparecer o direito de reivindicá-los. O abandono dos lotes urbanos caracteriza uso anti-social da propriedade, afastado que se apresenta do princípio constitucional da função social da propriedade. Permanece, todavia, o direito dos proprietários de pleitear indenização contra quem de direito. (TJSP - 8aㅡ. Cam., Ap. Cível n. 212.726-1-8, São Paulo, Rel. Des. José Osório, j. 16.12.1994, v.u.)

40 RUY RUBEM RUSCHEL afirma que o descumprimento da função social da propriedade implica na perda do direito de propriedade, equiparando o exercício anti-social da propriedade ao abandono do bem, em conformidade com a configuração daquela como elemento constitutivo da titularidade. "Afinal, se o titular abandonou o imóvel rural, deixando-o sem função social, perdeu sua propriedade antes da desapropriação; o ato expropriatório terá por objetivo tão somente integrá-lo de imediato no domínio da União e indenizar os custos acaso investidos pelo ex-dono. Já se vê que existe uma diferença de natureza entre a indenização que cabe nas desapropriações por necessidade e utilidade pública (art. 590 do CC) e aquela das desapropriações de imóveis rurais por interesse social. No $1^{\circ} \mathrm{caso}$, o poder pú blico indeniza pelo preço ("compra" a propriedade); mas no $2^{\circ}$, indeniza apenas os custos. Esta é que seria a razão do tratamento de exceção e desigual feito no art. 184 da CF, em confronto com a regra genérica do art. $5^{\circ}$, inc. XXIV da mesma carta.". RUSCHEL, Ruy Rubem. O Direito Público em tempos de crise. Porto Alegre: Sagra-Luzzatto, 1997.

41 "Só recebeu do ordenamento jurídico aquele direito de propriedade na medida em que respeite aquelas obrigações, na medida que em que respeite a função social do direito de propriedade. Se o proprietário não cumpre e não se realiza a função social da propriedade, ele deixa de ser merecedor de tutela por parte do ordenamento jurídico, desaparece o direito de propriedade" PERLINGIERI, Pietro. Introduzione ala problemática della 'propprietà'. Camerino, 1970. Apud in SILVEIRA, op. cit., p. 14. 
outros termos, já não há mais, no caso, bem que possa, juridicamente, ser objeto de direito de propriedade (...) não há, na hipótese propriedade que não cumpre sua função social 'propriedade' desapropriável. Pois é evidente que só se pode desapropriar a propriedade; onde ela não existe, não há o que desapropriar. ${ }^{42}$

"O direito de propriedade não pode ser analisado individualmente, fora do seu contexto social. O bem não utilizado ou mal utilizado é constante motivo de inquietação social. A má utilização da terra e do espaço urbano gera violência". ${ }^{43}$ Nesse contexto, percebe-se a função nuclear do direito de propriedade - com maior ênfase à imóvel - na estruturação socioeconômica da própria sociedade. A utilização da propriedade em desacordo com a sua função social - aqui também compreendida a sua função ambiental -, expressa na Lei Maior, acarreta em desordem de caráter socioeconômico na estrutura societária.

Nesse contexto, Jacques Alfonsin aponta para o não-cumprimento da função social da propriedade como caracterizador de abuso de direito e violação dos direitos humanos fundamentais à moradia e à alimentação de não-proprietários. Tal entendimento reforça a vinculação direta existente entre o direito de propriedade e a concretização dos direitos humanos fundamentais.

Existe um "território interior não dominial", portanto, constituído pelos direitos humanos fundamentais à alimentação e à moradia de não proprietários, que coincide com o território dominial que qualquer proprietário titule sobre a terra enquanto bem de produção, aí se estendendo ao mesmo tempo, no mesmo lugar (...) Quando se estabelece um conflito sobre terra, enquanto bem de produção, envolvendo, de um lado, direitos humanos fundamentais, e de outro, direitos patrimoniais, não havendo outra saída que não a do sacrifício de algum deles, os sacrificados deverão ser os patrimoniais. ${ }^{44}$

O conceito de propriedade está mais próximo hoje da noção de obrigação do que de da concepção clássica de direito real. ${ }^{45} \mathrm{~A}$ partir da ingerência da normativa principiológica constitucional, o caráter absoluto do direito de propriedade foi se

${ }^{42}$ GRAU, Eros Roberto. A ordem econômica na Constituição de 1988 - interpretação e crítica. São Paulo: Revista dos Tribunais, 1990, p. 316.

${ }^{43}$ VENOSA, Sílvio de Salvo. Direitos Reais. São Paulo: Atlas, 2001, p. 141.

44 ALFONSIN, Jacques Távora. O acesso à terra como conteúdo de direitos humanos fundamentais à alimentação e à moradia. Porto Alegre: Fabris, 2003, p. 267.

45 "O conceito de propriedade, ao contrário do que possa parecer, está muito mais próximo da noção de obrigação do que desta noção clássica de direito real, tal como hoje se percebe." FACHIN, Luiz Edson. Teoria crítica do Direito Civil. Rio de Janeiro: Renovar, 2000, p. 109. 
relativizando aos poucos, a ponto de hoje se reconhecer no direito de propriedade uma natureza obrigacional. ${ }^{46} \mathrm{~A}$ relação prestacional se dá entre o proprietário do bem e toda a coletividade.

O exercício do direito de propriedade encontra o seu limite e o seu conteúdo material no equilíbrio das relações sociais. Quando verificada a incompatibilidade da utilização da propriedade individual frente ao interesse social, o segundo deve prevalecer. Esta é a essência do princípio e do direito fundamental da função social da propriedade. A concretização da função social da propriedade na práxis jurídica é condicionante para a concretização dos valores mais elementares do Estado social e democrático de Direito, entre eles o bem estar social, o direito à moradia, a dignidade da pessoa humana e o direito à vida. ${ }^{47}$ Nesse contexto, a decisão proferida pelo juiz de direito gaúcho Luis Christiano Enger Aires em sede de liminar de ação de reintegração posse, a qual foi negada em favor do direito de inúmeras famílias de agricultores rurais sem-terra, em detrimento do direito patrimonial do proprietário, afirmando o direito daquelas à vida digna e ao mínimo existencial.

Assim, de um lado, temos o direito de propriedade e o conseqüente prejuízo patrimonial que eventualmente seja causado aos autores pela ação dos requeridos; e, de outro, o direito à vida digna dos requeridos que buscam obrigar o Estado brasileiro a cumprir - com urgência - as tarefas que lhe foram impostas constitucionalmente e que têm sido historicamente postergadas. Não tenho dúvidas

\footnotetext{
46 "Ocorre que a permeabilidade verificada por parte dos direitos reais, para com os obrigacionais, traz certos deveres do respectivo titular para com a coletividade em que se insere, verificáveis topicamente, em prol de um princípio que o vincula no âmbito proprietário: o princípio da função social". ARONNE, op. cit., p. 138. O professor Aronne traz à colação um entendimento jurisprudencial que caracteriza a obrigação do proprietário para com a coletividade no exercício do seu direito. AÇÃO PÚBLICA. POLUIÇÃO AMBIENTAL. OBRAS NÃO REALIZADAS. OBRIGAÇÃO DE FAZER. MULTA. A empresa que na sua atividade industrial provoca a emissão de fumaça que polui atmosfera e lança em rio - Paraíba do Sul -, diretamente, vários efluentes líquidos e que, intimada para realizar obras de proteção ao meio ambiente, não as realiza integralmente em prazo superior a uma década, contado da primeira intimação, deverá ser compelida a fazê-las em certo prazo, sujeitando-se ao pagamento de multa por eventual atraso. (Ap. Cível 3.379/90, 8a C. Cível do TJRJ, v. u., Rel. Des. Geraldo Batista, 18.06.91)
} 
de que, havendo necessidade de um desses direitos ser sacrificado, deve ele ser o patrimonial, considerando que a Constituição da República (art. 1ํㅡㄹ II e III, e art. 3ํ) reconheceu aquilo que a doutrina e a jurisprudência alemãs chamam de 'garantia estatal do mínimo existencial' ou 'garantia positiva dos recursos mínimos para uma existência'. E como garantir esse mínimo sem atentar para a necessidade de preservar os bens fundamentais (trabalho, moradia, educação, saúde) que correspondam à qualidade humana, sem os quais sequer se poderia falar de pessoa humana, consoante afirmado por Ricardo Luis Lorenzetti. ${ }^{48}$

A partir da importância substancial do direito de propriedade para a constituição da estrutura social, não se pode deixar de reconhecer a relação intrínseca entre dignidade da pessoa humana e propriedade. No contexto socioeconômico vivenciado pela sociedade contemporânea, não se pode conceber a realização das condições mínimas existências sem 0 acesso ao direito de propriedade - considerando que de tal direito decorre o acesso à moradia, à alimentação, à renda mínima, ou seja, ao mínimo existencial assegurado a todos pela Carta Constitucional de 1988.

Até mesmo o direito de propriedade - inclusive e especialmente tendo presente o seu conteúdo social consagrado no constitucionalismo pátrio - se constitui em dimensão inerente à dignidade da pessoa, considerando que a falta de uma moradia decente ou mesmo de um espaço físico adequado para o exercício da atividade profissional e evidentemente acaba, em muitos casos, comprometendo gravemente - senão definitivamente - os pressupostos básicos para uma vida com dignidade. ${ }^{49}$

47 BARROSO estabelece o conceito de dignidade da pessoa humana, considerando o mínimo existencial e os elementos que o constituem como padrão mínimo para uma existência digna. "Dignidade da pessoa humana expressa um conjunto de valores civilizatórios incorporados ao patrimônio da humanidade. $O$ conteúdo jurídico do princípio vem associado aos direitos fundamentais, envolvendo aspectos de direitos individuais, políticos e sociais. Seu núcleo material elementar é composto do mínimo existencial, locução que identifica o conjunto de bens e utilidades básicas para a subsistência física e indispensável ao desfrute da própria liberdade. Aquém daquele patamar, ainda quando haja sobrevivência, não há dignidade. O elenco de prestações que compõe o mínimo existencial comporta variação conforme a visão subjetiva de quem o elabore, mas parece haver razoável consenso de que inclui: renda mínima, saúde básica e educação fundamental. Há ainda, um elemento instrumental, que é o acesso à justiça, indispensável para a exigibilidade e efetivação dos direitos". BARROSO, Luís Roberto. Fundamentos teóricos e filosóficos do novo direito constitucional brasileiro Pós-modernidade, teoria crítica e pós-positivismo. Revista do Ministério Público do Estado do Rio Grande do Sul, n. 46. Porto Alegre: Metrópole, 2002, p. 59.

${ }^{48}$ Sentenças: Rio Grande do Sul. Publicada pelo Poder Judiciário do Estado do Rio Grande do Sul e AJURIS, n. 7/8, Jun-Dez/2002. Porto Alegre: Departamento de Artes Gráficas, 2002, p. 170.

49 SARLET, Ingo Wolfgang. Dignidade da Pessoa Humana e Direitos Fundamentais na Constituição de 1988. Porto Alegre: Livraria do Advogado, 2001, p. 90-91. 
O seu descumprimento, como se registra em grande medida no contexto social brasileiro, acarreta em profunda inquietação e desarmonia social. $^{50} \mathrm{O}$ surgimento de movimentos populares ${ }^{51}$ de grande expressão e legitimidade na sociedade brasileira nas últimas décadas reflete de forma clara e objetiva o acúmulo desta angustia social em relação à forma como se dá a distribuição da renda e, conseqüentemente, da propriedade no Brasil.

$\mathrm{Na}$ esteira dos limites individuais e coletivos da propriedade, 0 Desembargador do Tribunal de Justiça do Rio Grande do Sul Carlos Rafael Dos Santos Júnior ${ }^{52}$, ao comentar as últimas decisões jurisprudenciais relativas às ocupações de terra do Movimento dos Sem Terra - MST $^{53}$ e rebater críticas dos defensores do latifúndio e da criminalização dos movimentos sociais, afirma que: “(...) como a Constituição Federal determina em seu art. 5, inciso XXIII, o direito de propriedade possui limitações, não é absoluto, aliás, como qualquer direito não pode ser. E somente a propriedade que atender a sua função social terá a máxima garantia. É o que está na lei, e que tem sido atendido pelas decisões ventiladas." 54

50 GESTA LEAL aponta para a falta de legitimidade da ordem jurídica formal, quando constatada a mobilização social contra o estabelecido. "Os conflitos sociais surgidos no campo e na cidade, unidos à crise de identidade e legitimidade do Estado de Direito em geral, em especial do Estado Brasileiro, enquanto evidenciam a existência de opiniões, comportamentos, desejos e crenças múltiplos e contraditórios, convivendo no mesmo tecido social e revelando uma profunda marginalização humana, denunciam o profundo questionamento do poder e da ordem estabelecida. Tal questionamento pode ser encontrado em determinados andares sociais ou populares que, à revelia da ordem estatal estabelecida, inauguram práticas de resolução dos seus conflitos e problemas a partir de uma normatividade própria e informal - quando não ilegal. A forma pela qual esta ordem estatal é desconsiderada, no decorrer de determinadas manifestações de massa, acusa a contestação da legitimidade formal estabelecida, fazendo visível a presença de um contra-poder e de uma contra-ordem". LEAL, Rogério Gesta. A função social da propriedade e da cidade no Brasil. Porto Alegre/Santa Cruz do Sul: Livraria do Advogado/Edunisc, 1998, p. 76.

51 Entre outros: o Movimento dos Trabalhadores Rurais Sem Terra - MST, o Movimento dos Atingidos por Barragem - MAB, o Movimento dos Sem-teto.

${ }^{52}$ Destaco a ementa de julgamento recente em que participou o eminente desembargador. APELAÇÃO CÍVEL. REINTEGRAÇÃO DE POSSE. AUSÊNCIA DE PROVAS. PRINCÍPIOS DA RAZOABILIDADE E PROPORCIONALIDADE QUE ORIENTAM A ADMINISTRAÇÃO PÚBLICA. INATENDIDOS. Restam inatendidos os princípios da razoabilidade e da proporcionalidade, bem ainda o da função social da propriedade, cujos quais devem ser integrados ao caso concreto, para estender à suplicante a verdadeira Justiça. Ausente prova da posse anterior, certo que o título de propriedade, tão-somente, não se presta a tanto. (TJRS, Ap. Cível n. 70004913729/Bento Gonçalves, 19ª Câmara Cível, Rel. Des. Guinther Spode, julgado em 15 de abril de 2003)

53 Para compreender a processo histórico do Movimento dos Trabalhadores Rurais Sem-Terra, ver MARTINS, José de Souza. Reforma Agrária - O impossível diálogo. São Paulo: Editora da Universidade de São Paulo, 2000, com uma postura crítica frente ao movimento; e FERNANDES, Bernardo Mançano. O MST no contexto da formação camponesa no Brasil. In: STROZAKE, Juvelino José (Org.). A questão agrária e a justiça. São Paulo: Revista dos Tribunais, 2000, p. 15-87.

\footnotetext{
${ }^{54}$ Artigo publicado no Jornal Correio do Povo, em 23 de abril de 2002, na seção Opinião.
} 
A relação traçada por Garrido Peña entre propriedade, interesse social e liberdade expressa de forma clara como a concepção absolutista da propriedade privada acarreta em inquietações e injustiças sociais.

En esto consiste la libertad de propiedad en apropiarse de la libertad de otros. Decir que algo es de propiedad privada nos es indicar quine puede gozar de ese algo, sino ordenar quien no puede gozar de ese algo. La libertad de propiedad es una máquina de producción de la lógica de la exclusión y la segregación social. Aquí tenemos una primera característica de la teoría moderna del valor jurídico: vale lo que excluye, lo que priva, lo que produce e induce a relaciones de dominación y escasez. ${ }^{55}$

A Constituição Federal de 1988 opera na ordem jurídica brasileira uma unidade sistemática e axiológica, orientada por uma rede de princípios e valores constitucionais fundamentais que filtram toda a esfera jurídica infraconstitucional, estabelecendo o que integra e o que não é recepcionado pelo sistema jurídico. Um destes princípios fundamentais é a função social da propriedade.

A Constituição Federal de 1988 consigna, de forma abrangente e sistemática, uma série de princípios gerais, fundamentais ou jurídicos, que fundamentam, orientam e caracterizam o nosso sistema político, o modelo de Estado, os direitos e garantias fundamentais e a ordem econômica, como estruturas-mestras do sistema jurídico. Entre os direitos e garantias fundamentais e entre os princípios que caracterizam a ordem econômica, encontra-se em relevo o princípio da função social da propriedade. ${ }^{56}$

O fenômeno jurídico da constitucionalização do Direito Civil impõe uma racionalidade de inversão de valores no regime jurídico da propriedade clássica, voltando o centro do ordenamento jurídico para a afirmação da dignidade da pessoa humana. Nesse contexto, a função social da propriedade impõe uma roupagem mais humana à propriedade, constituindo-se de instrumento concretizador da dignidade da pessoa humana e do bem-estar social.

Quanto ao aspecto funcional, o princípio da função social da propriedade desempenha satisfatoriamente todas as cinco funções anteriormente assinaladas isto é, interpretativa, integrativa, diretiva, limitativa e prescritiva - todas elas

\footnotetext{
55 PEÑA, Francisco Garrido. De como la ecologia política redefine conceptos centrales de la ontologia jurídica tradicional: libertad y propiedad. In $\mathbf{O}$ novo em Direito Ambiental. Marcelo Dias Varella e Roxana Cardoso Brasileiro Borges (Organizadores). Belo Horizonte: Del Rey, 1998, p. 214.

56 MORAES, José Diniz de. A função social da propriedade e a Constituição Federal de 1988. São Paulo: Malheiros, 1999, p. 43.
} 
compreendidas na função normativa. Ocupa espaço na interpretação não apenas dos casos em que a propriedade está diretamente vinculada à causa (a dúvida deve ser resolvida sempre em favor da situação que melhor atende à sua função social), mas muito mais naquelas demandas em que o interesse social deve prevalecer sobre o interesse do proprietário - v. g., meio ambiente, habitação, urbanismo etc. ${ }^{57}$

No Brasil, a primeira constituição federal a consagrar de forma expressa, a função social da propriedade no seu escopo, foi a Constituição Federal de $1946^{58}$, ainda sob forte influência do texto constitucional alemão da República de Weimar (1919) ${ }^{59}$, precursor do referido instituto jurídico no cenário constitucional romano-germânico. ${ }^{60}$ No entanto, a sua inserção no catálogo dos direitos e garantias fundamentais, sedimentando tal instituto no núcleo normativo fundamental do Estado social e democrático de Direito brasileiro, deu-se com a última Carta da República (1988).

A função social condiciona o direito de propriedade a um exercício harmônico e equilibrado da titularidade frente ao interesse individual do proprietário e o interesse da coletividade. É reconhecida à propriedade uma finalidade maior dentro de toda a estrutura societária e constitucional brasileira, que é a realização do bem-estar social, da justiça social e da dignidade da pessoa humana. A partir dessas compreensões, verifica-se uma linha tênue entre os limites do interesse social e do interesse individual. Nesse sentido, é preciso firmar distinção entre o direito subjetivo individual do proprietário e o direito subjetivo público que recaem sobre a propriedade.

57 MORAIS, José Luis Bolzan de. O surgimento dos interesses transindividuais. Revista Ciência e Ambiente - Universidade Federal de Santa Maria, n. ${ }^{\circ} 17$, Jul-Dez/1988, p. 65.

58 Verifica-se no Capítulo "Da Ordem Econômica e Social", art. 147: "O uso da propriedade será condicionado ao bem-estar social. A lei poderá, com observância do disposto no art. 146, § 16, promover a justa distribuição da propriedade com igual oportunidade para todos".

59 "O primeiro texto constitucional a consignar expressamente a idéia de função social foi a Constituição republicana alemã de 1919 (Constituição de Weimar). A constituição alemã de 1949 incorporou, ipsis verbis, a disposição da Carta de Weimar relativa ao princípio da função social."MORAES, op. cit., p. 33.

60 Aponta-se aqui o texto do art. 14 da Lei Fundamental alemã de 1949, que incorporou o conteúdo da Constituição de Weimar sobre a função social da propriedade. "Art. 14 (Propriedade, direito de sucessão e expropriação). (1) A propriedade e o direito de sucessão hereditária são garantidos. O seu conteúdo e os seus limites são determinados por lei. (2) $A$ propriedade obriga. $O$ seu uso deve ao mesmo tempo servir para o bem-estar geral. (3) A expropriação só é lícita se for efectuada no interesse geral. Pode ser efectuada unicamente por lei ou com base numa lei que estabeleça o modo e o montante da indemnização. A indemnização deve ser determinada através da ponderação justa dos interesses gerais e dos das pessoas afectadas. Em caso de divergência acerca do montante de indemnização admite-se o recurso via judicial junto dos tribunais comuns". (grifos meus). ROGEIRO, Nuno. A Lei Fundamental da República Federal da Alemanha - Com um ensaio e anotações de Nuno Rogeiro. Coimbra: Coimbra Editora, 1996, p. 141. 
Da mesma forma que é conferido um direito subjetivo individual para o proprietário reclamar a garantia da relação de propriedade, é atribuído ao Estado e à coletividade o direito subjetivo público para exigir do sujeito proprietário a realização de determinadas ações, a fim de que a relação de propriedade mantenha sua validade no mundo jurídico. $\mathrm{O}$ direito de propriedade deixa de ser, então, exclusivamente um direito garantia do proprietário e se torna um direito garantia da sociedade. ${ }^{61}$

Destaca-se que o interesse social (direito subjetivo público) em relação à determinada propriedade privada, pode ser de maior ou menor grau, dependendo sempre da relevância social, ou mesmo ambiental, do bem jurídico em questão. A propriedade, por exemplo, que recaia sobre área de preservação permanente ${ }^{62}$, reconhecendo-se o valor ambiental e social da preservação dessa área para todo o ecossistema ${ }^{63}$ onde está inserida, deve receber uma valoração social diferente se comparada a outra área sem a mesma significância jurídica. A base conceitual da propriedade está na Constituição, cabendo ao operador jurídico equacionar o equilíbrio entre o individual e o social. Se, diante de um confronto de interesses, um dos dois tiver que ceder espaço ao outro, este será o interesse individual.

Outro exemplo paradigmático é o do latifúndio improdutivo ou, mesmo produtivo, que não atenda aos incisos do art. $186^{64}$ da Constituição Federal de 1988. Não correspondendo o exercício da propriedade rural às determinações constitucionais, levando-se em conta a grande importância socioeconômica da agropecuária para o Brasil, bem como a insustentável problemática e demanda social por terra e reforma agrária, deve prevalecer o interesse social sobre o interesse individual do proprietário.

Nesse ponto, é oportuna a lição de Ricardo Aronne que, ao divergir da doutrina civilista clássica ${ }^{65}$, aponta para a autonomia conceitual existente entre

61 DERANI, Cristiane. Função ambiental da propriedade. In Revista de Direitos Difusos, Vol. 3. Liberdade, SP: ADCOAS/IBAP, Out/2000, p. 267.

${ }^{62}$ Art. $1^{\circ}, \S 2^{\circ}$, II, do Código Florestal.

63 Inserido o ser humano nesse contexto.

64 I - aproveitamento racional e adequado; II - utilização adequada dos recursos naturais disponíveis e preservação do meio ambiente; III - observância das disposições que regulam as relações de trabalho; IV exploração que favoreça o bem-estar dos proprietários e dos trabalhadores.

${ }^{65}$ A doutrina clássica não admite uma distinção material entre os referidos conceitos, admitindo como sinônimos propriedade e domínio. "A terminologia atual aceita domínio e propriedade como sinônimos, embora, como acentuado, se reserve com maior uso o termo propriedade para os bens imateriais, referindo-se o domínio de forma mais ampla aos bens corpóreos e incorpóreos". VENOSA, Sílvio de Salvo. Direitos Reais. São Paulo: Atlas, 2001, p. 147. 
propriedade e domínio. ${ }^{66} \mathrm{~A}$ partir do conceito de propriedade, reconhece-se uma relação de cunho obrigacional entre o proprietário e todo o conjunto da sociedade (caráter erga omnes). Nesse contexto, ao passo que é exigido o direito de abstenção de terceiros para com o direito individual de propriedade, o proprietário é obrigado a atender à função social da titularidade no exercício do seu direito como contraprestação.

Ao mesmo tempo existe uma obrigação do proprietário de fazer a propriedade atender sua função social, do qual são credores o Estado e a coletividade (pluralizada ou singularizada). Por tanto, a obrigação da propriedade é bilateral, devendo ser atendida para que seja oponível. (...) Ao se obrigacionalizar, opera-se a "repersonalização" despatrimonializante do respectivo direito real, cediço que ao direito obrigacional não advém resquícios de absolutividade, bem como se opera uma contrapartida de deveres em vista do adimplemento, que se orientarão teleologicamente em vista do princípio da função social. ${ }^{67}$

A função social da propriedade, na proporção e na relevância deste instituto jurídico para todo o conjunto da sociedade, estabelece uma nova relação de titularidade que se firma entre o cidadão-proprietário e toda a coletividade. É no equilíbrio e na proporcionalidade desta relação que está o limite e a razão existencial do direito de propriedade na nova ordem jurídica contemporânea.

Assim como não existe concepção de Direito para o homem só, isolado em uma ilha, não existe propriedade, como entidade social e jurídica, que possa ser analisada isoladamente. A justa aplicação do direito de propriedade depende do encontro do ponto de equilíbrio entre o interesse coletivo e o interesse individual. Isso nem sempre é alcançado pelas leis, normas abstratas e frias, ora envelhecidas pelo ranço de antigas concepções, ora falsamente sociais e progressistas, decorrentes de oportunismos e interesses corporativos. Cabe à jurisprudência responder aos anseios da sociedade em cada momento histórico. ${ }^{68}$

Como se pode perceber da leitura da citação, a função social da propriedade é elo de conexão entre o indivíduo e toda a sociedade, a partir de um dos elementos mais importantes e estruturantes da ordem socioeconômica do Estado social e

\footnotetext{
66 "O domínio tem por objeto uma coisa e suas faculdades, não tendo um sujeito passivo, já a propriedade, tem por objeto uma prestação, tendo sujeito passivo e não sendo de natureza real. Aí está o pontochave da 'repersonalização' buscada, onde se funcionaliza o direito real, pela via do seu instrumentalizador". ARONNE, Ricardo. Propriedade e Domínio. Reexame Sistemático das Noções Nucleares de Direitos Reais. Rio de Janeiro: Renovar, 1999, p. 91.
}

${ }^{67}$ ARONNE, op. cit., p. 94.

${ }^{68}$ VENOSA, Sílvio de Salvo. Direitos Reais. São Paulo: Atlas, 2001, p. 141. 
democrático de Direito, que é a propriedade. No entanto, diferentemente do caráter que lhe foi atribuído em cartas constitucionais passadas, o direito de propriedade foi retirado do seu invólucro privatista para incorporar caráter humano (nãopatrimonialista) e coletivo. $O$ interesse social passa a ser o grande sujeito tutelado no âmbito do direito de propriedade, respeitando sempre, quando legítimo, a dimensão individual do direito. Constata-se que, de mero coadjuvante na órbita privada na concepção liberal, o interesse social e a dignidade humana passam a ser os grandes protagonistas do Direito Civil contemporâneo.

O direito de propriedade só se legitima e é recepcionado pela ordem jurídica como direito fundamental, na medida em que atenda à sua função social - aqui se agrega também a dimensão ambiental da função social -, pois só assim cumprirá o seu papel constitucional e estará a serviço da vida e da dignidade humana. ${ }^{69}$ Portanto, somente a propriedade que atenda às suas funções constitucionais é que será reconhecida pelo direito e integrará a ordem jurídica fundamental. ${ }^{70}$ Não se pode jamais olvidar o jurista do Estado social e democrático de Direito que o direito de propriedade também é um direito à propriedade, cabendo à ordem jurídica garantir a todos os cidadãos as condições existenciais mínimas, dentre as quais estão, respectivamente nos âmbitos urbano e rural, os direitos à moradia, à alimentação e à terra, representações fundamentais do direito à propriedade.

69 "Quando a propriedade não se apresenta, concretamente, como uma garantia da liberdade humana, mas, bem ao contrário, serve de instrumento ao exercício de poder sobre outrem, seria rematado absurdo que se the reconhecesse o estatuto de direito humano, com todas as garantias inerentes e essa condição". In COMPARATO, Fábio Konder. Direitos e Deveres Fundamentais em Matéria de Propriedade, conferência proferida no $1^{\circ}$ Congresso de Direitos Humanos, Brasília - DF, 1997, mimeo. Apud in SILVEIRA, Domingos Sávio Dresch da. A propriedade agrária e suas funções sociais. In $\mathbf{O}$ direito agrário em debate. Domingos Sávio Dresch da Silveira e Flávio Sant'Ánna Xavier (organizadores). Porto Alegre: Livraria do Advogado, 1998, p. 17.

70 "Ademais, em se tomando como referencial o critério da fundamentalidade substancial (material) e, nesta quadra, a conexão com o direito a uma existência digna, o direito à moradia poderá assumir, em diversas situações, posição preferencial em relação ao direito de propriedade, no mínimo para justificar uma série de restrições a este direito, que, de resto - e de acordo com previsão constitucional expressa - encontra-se limitado pela sua função social, de tal sorte que, já há algum tempo - expressiva doutrina sustenta que apenas a propriedade socialmente útil (isto é, que cumpra sua função social) é constitucionalmente tutelada (...) Por outro lado, já se apontou - com acuidade e sensibilidade - para uma noção de propriedade tutelada na medidade em que cumpre precisamente uma função existencial e não meramente patrimonial". SARLET, Ingo Wolfgang. O direito fundamental à moradia na Constituição: algumas anotações a respeito de sei contexto, conteúdo e possível eficácia. In: Arquivos de Direitos Humanos, Vol. 4. Organizadores: MELLO, Celso de Albuquerque; TORRES, Ricardo Lobo. São Paulo/Rio de Janeiro: Renovar, 2002, p. 157. 